Ernesto Vidal Prada*

\title{
Una pedagogía para el objeto de diseño industrial digital ${ }^{1 .}$
}

\author{
Cómo citar:
}

Vidal, E. (2018). Una pedagogía para el objeto de diseño industrial digital. Designia, 6(1), 117-123.

1“El texto está basado en algunos planteamientos abordados y revisados a partir de la tesis de Maestría titulada "El vacío del objetoimagen. - Una reflexión crítica acerca de las imágenes digitales en el diseño industrial". - Vidal E. (2015) - Maestría en Diseño Comunicacional, FADU, UBA. (Buenos Aires, Argentina).

*Diseñador Industrial, UIS. Especialista en Teoría del Diseño Comunicacional, UBA. Magister en Diseño Comunicacional, UBA. Actualmente Docente Programa Diseño Industrial, Universidad de Investigación y Desarrollo UDI (Bucaramanga). Docente Investigador Grupo de Investigación Paloseco. Adscrito a Colciencias - Categoría C). E-mail: evidal1@udi.edu.co ORCID: 0000-0003-3550-7525

\section{Palabras clave:}

Diseño industrial, objeto de diseño, pedagogía

\section{Key words:}

Industrial design, design object, pedagogy.

Recibido: $12 / 06 / 2018$

Aceptado: 17/10/2018

\section{Resumen:}

Para la sección "Disertaciones sobre Diseño del Vol 6, № 1 de la revista Designia, el autor invitado presenta un artículo corto de reflexión, en el que se discute acerca de la enseñanza y aprendizaje del diseño industrial en contextos digitales.

En este caso, a partir de la propuesta pedagógica titulada "Aulas con sentido" en la cual se plantea un esquema básico y punto de partida para pensar el uso de herramientas digitales dentro de cursos académicos de un programa de Diseño Industrial.

De acuerdo con la experiencia descrita, la reflexión implica la realidad de la disciplina más allá del uso de la tecnología, en este caso a partir de la representación digital del objeto de diseño de diseño, su función comunicativa y vinculación con el contexto. 
Abstract

For the section "Dissertations on Design of Volume 6, $\mathrm{N}^{\circ} 1$ of Designia magazine, the invited author presents a short article of reflection, in which the teaching and learning of industrial design in digital contexts is discussed. In this case, based on the pedagogical proposal entitled "Aulas con sentido", which presents a basic outline and starting point to think about the use of digital media in the academic courses of an Industrial Design program.

In accordance with the experience described, the reality of the discipline is discussed beyond the use of technology, in this case, in the digital representation of the design object, its communicative function and its connection with the context.

A manera de introducción: Nuevas perspectivas y miradas desde lo digital

La llegada y popularización del uso de herramientas digitales (software) para el proceso creativo del diseñador industrial trajo consigo al interior de la disciplina, y en su ejercicio cotidiano, la existencia de una sensación de vacío asociada a la representación de objetos mediante imágenes digitales sintéticas conocidas como renders de diseño. Esta sensación de vacío exige el reto de pensar los alcances actuales y futuros del diseñador, y particularmente desde una formación académica dilucidar, desde lo digital, la construcción de nuevas realidades y nuevos replanteamientos para la construcción del universo objetual. Lo digital nos enfrenta al reto de un mundo manipulado y pensado desde el dominio de lo visual.
Reconocer esta sensación de vacío nos ofrece el motivo para construir desde lo posible y desde la emoción cotidiana, desde la experiencia, el futuro.

El diseño busca entender el planteamiento de su ejercicio como proceso, como método, independiente de sus propuestas objetuales o soluciones concretas. El diseñador, en la definición de su disciplina, tiene el objetivo de reformular la idea del objeto en su practicidad, pero también, la reformulación del objetivo de su actividad como diseñador (Fernández; 2013). Las tareas, retos y sentido particular del diseño seguirán siendo los mismos, pero su enfoque a futuro debe rescatar los valores humanos. Una pedagogía para el objeto de diseño industrial digital " es propuesta a manera de estrategia que permita superar esta sensación de vacío. Su eje central gira en proponer diversas 
herramientas de configuración del proceso de diseño, relacionadas con el uso de tecnologías digitales, y que desde lo pedagógico busquen aportar al desarrollo del proyecto de diseño una carga emocional que logre transmitir la importancia del objeto en la realidad, y en la construcción de futuros posibles.

Transformar la sensación de vacío es una posición que debe ser asumida desde la academia, desde el aula, desde cualquier lugar cuyo objetivo sea la transmisión de conocimientos. Una pedagogía cuyo fin no es la repetición de conocimientos o la operación de tecnologías, sino que busca la construcción de mundos posibles a partir de la recuperación de la conciencia usurpada por la tecnología. Un proceso de enseñanza en pro de una "permanente ruptura intencional de sentidos y significados" (Quintar, 2006, pág. 41) cuyos objetivos sean actualizables con el tiempo y operables desde la práctica cotidiana del diseño industrial y su vinculación con herramientas digitales, se busca recuperar la esencia del objeto de diseño como elemento comunicador de mensajes.

La sensación de vacío obliga al diseñador hacia un auto cuestionamiento sobre la realidad de su disciplina más allá del uso de la tecnología. El render de diseño digital, entendido como representación superficial y estética del objeto, debe generar en el diseñador la búsqueda por un campo emocional asociado al uso del objeto mismo, a su práctica y que no está incluido ni presente en la pantalla. Una pedagogía que piense el objeto de diseño industrial digital pretende cuestionar el carácter representacional impuesto por las herramientas digitales, en el sentido de buscar en dichas imágenes la presencia de lo real (la realidad) en la propuesta de diseño. Esta situación implica entonces rescatar un pensamiento crítico y ético asociado al quehacer mismo del diseñador y su auto - reflexión en torno a la implementación de los procesos digitales mismos dentro del desarrollo del proyecto. Siguiendo las palabras de Aicher (2001, pág.24) la reflexión metodológica en torno al ejercicio práctico del diseñador más allá de su implementación (como pasos lógicos) y como revelación (el render digital) debe privilegiar la búsqueda de unas "raíces del diseño", por encima de un enfoque hacia consumo.

\section{La potencia de lo pedagógico}

Las respuestas a estos cuestionamientos se proponen mediante la búsqueda y el recorrido de caminos metodológicos que permitan dar una nueva mirada al proceso tradicional del diseño y que implique el uso de herramientas digitales. Estos caminos metodológicos buscan la necesidad de devolver al objeto de diseño a una realidad cotidiana, evitando así que el fin último sea la visualización en una pantalla. Caminos metodológicos llevados a la práctica mediante el desarrollo de ejercicios pedagógicos, que buscan la generación de contextos de sentido (identidad) como una comprensión del mundo cuyo único fin es revelar la realidad.

Esta pedagogía denominada "Aulas con sentido" tiene que ver, directamente con la estructuración de una nueva mirada para afrontar el proyecto de diseño con el aprovechamiento de las ventajas de la tecnología digital. Mirada que se construye desde el mismo cuestionamiento hacia lo real, poco a poco, mediante las herramientas metodológicas planteadas y que se concretiza en una concepción comunicacional del proyecto de diseño. Esta estructuración de la mirada tiene que ver con un retorno hacia a lo real, pero también con volver a lo básico de la disciplina en el ejercicio de proponer soluciones de 
diseño. El computador, la pantalla, son vistos como herramientas necesarias para nuevos escenarios que posibilitan los proyectos de diseño. Una pedagogía pensada desde el uso de medios digitales, que permite entender la experiencia del diseño y su práctica "como una práctica social, como parte de la cultura, y al conocimiento, como producción de sentidos y significados que se construyen en la relación con el otro y con lo otro que la realidad nos muestra a la vez que nos oculta." (Quintar, 2008, pág. 27).

Una pedagogía del objeto de diseño industrial digital, factible de ser implementada en cualquier ámbito y escenario real pedagógico debe incluir dentro de su estructura un cruce de dos elementos fundamentales: un potencial creativo representado en caminos metodológicos que hablan del aprove- la forma en que nos acercamos a ella "determina de manera decisiva no solo la percepción del mundo presente, sino también de la sociedad futura" (Quintana, 2010, pág.10).

A manera de un esquema general (ver Figura N.1) se plantea una estructura básica de estos caminos metodológicos y herramientas emocionales propuestas, la cual se fundamenta en el reconocimiento de la sensación de vacío por el estudiante frente a la generación de objetos digitales ${ }^{2}$, y a partir de allí el establecimiento de una serie de preguntas que guían el proceso posterior de construcción del objeto digital (modelado y renderizado). Tres caminos metodológicos permiten encausar las posibles respuestas ante esta sensación inducida del vacío:

1.) Bosquejar la realidad (representar digitalmente la realidad del objeto más allá de su dimensión física; Ejemplo: representar usos, comportamientos particulares del objeto, etc.)

2.) Modelar el proceso (representar digitalmente el proceso de diseño como una abstracción del proceso productivo digital del objeto). 
3.) Renderizar el entorno (representar digitalmente las diferentes variables culturales que permiten contextualizar la propuesta de diseño). Finalmente son estos caminos metodológicos y su cruce con herramientas emocionales ${ }^{3}$ lo que permite la generación de esquemas digitales que conceptualizan y definen una propuesta de diseño más allá de un objeto - imagen digital o que termina en la pantalla de un computador o en cualquier medio impreso.

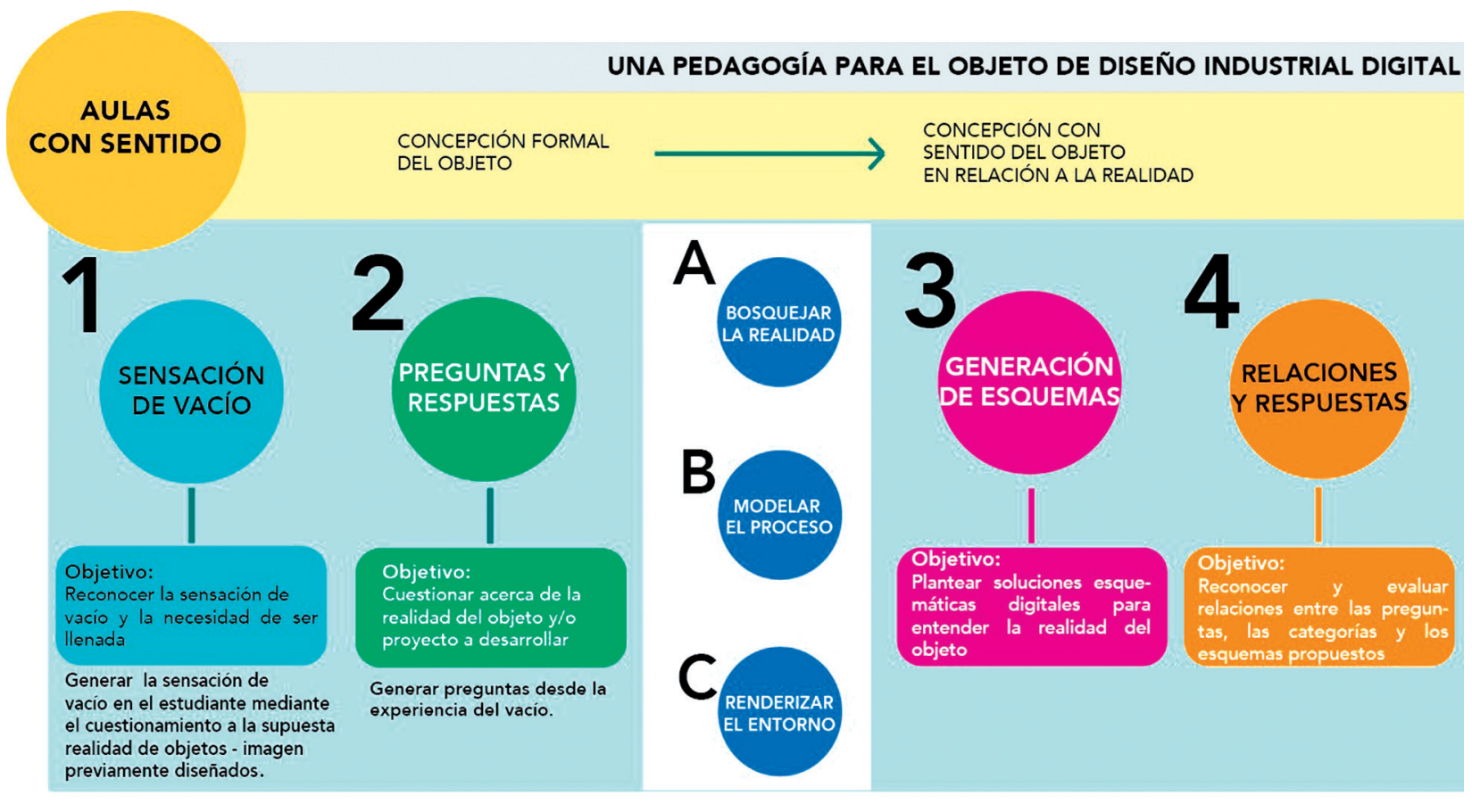

Figura 1. Esquema básico de la propuesta pedagógica. Fuente: autor.

${ }^{3}$ Se proponen de manera paralela tres herramientas emocionales, que a manera de alegoría con herramientas manuales son las que permiten estructurar, modelar y configurar la forma y apariencia del objeto digital propuesto. Estas herramientas son: a.) Lápices de tiempo (representar el objeto digital como un acontecimiento en el tiempo). b.) Arboles de conceptos (el uso de conceptos básicos que permiten estructurar propuestas de diseño digital.) c.) Mapas de realidad. (representación de contextos que permiten visualizar y comunicar el objeto digital). (Nota del autor) 


\section{A manera de conclusión}

Afrontar el salto entre la propuesta teórica y su implementación implica establecer un plan de acción constituido por pasos metodológicos, que pueden ser adaptados a circunstancias particulares de recursos, perfiles y planes desde la academia ${ }^{4}$. Una pedagogía que incluya nuevos imaginarios relacionados a procesos digitales le otorgará al diseñador las opciones y variables metodológicas necesarias para poder vincular el proyecto de diseño digital con la realidad del objeto. A su vez, esta pedagogía se puede convertir en una resignificación del proceso de diseño, donde las herramientas digitales son las que permitirán modelar el paso a paso a realizar, sin limitarse a un entorno virtual alejado de la realidad, sino que utiliza al máximo el poder de la pedagogía y de las herramientas digitales a la mano. La pantalla ya no es solo un mecanismo de visualización, sino que está asociada a un elemento que permite desplegar ${ }^{5}$ el proyecto mismo bajo lógicas que traspasan lo técnico y se soportan en lo poético y en lo humano.

Finalmente, una estrategia de implementación de la pedagogía planteada o de alguno de sus caminos metodológicos y herramientas emocionales busca la creación de objetos con sentido, entendiendo este planteamiento como un "volver a sentir" el objeto más allá de las herramientas tecnológicas y digitales (y el vacío generadas por ellas), incluso más allá de su medio de fabricación o materialidad. Sentir el objeto no se limita, entonces, a un -palpar- de las propiedades físicas del objeto, sino que busca entender al nivel y saber del diseñador digital la construcción y planteamiento de objetos desde la experiencia, la cultura y la memoria, en cada una de las fases por las que atraviesa el objeto en su ciclo de vida. Sentir el objeto retoma los planteamientos de Olalquiaga (2012) al pensar un territorio o espacio donde "el contacto mágico que pueda establecerse indirectamente refleja la capacidad humana para la abstracción, la memoria y la poesía." Los sentidos del objeto son propuestos como aquellos que lazos que enlazan estas instancias del objeto, en su método y en su uso, y que son desplegadas en la pantalla con fines comunicativos más que comerciales.

${ }^{4}$ La propuesta pedagógica "Aulas con sentido" plantea un esquema general básico y punto de partida para pensar el uso de herramientas digitales dentro de cursos académicos de un programa de diseño industrial. Su viabilidad e implementación real también dependen de variables propias del curso, de la institución y sus metodologías, y particularmente de la reflexión previa planteada frente a un proyecto de diseño. Así mismo influirán en esta implementación las variaciones tecnológicas (software y hardware) que decidan ser vinculadas a dicho proyecto. 


\section{REFERENCIAS BIBLIOGRÁFICAS}

Aicher, O. (2001). Analógico y digital. Barcelona, España: Editorial Gustavo Gili.

Fernández, R. (2011). El vacío de la teoría. En: Fernández, R. Mundo diseñado. Para una teoría crítica del proyecto total. Santa Fe, Argentina: Universidad Nacional del Litoral.

Olalquiaga, C. (2012). Se mira pero no se toca. El papel de lo táctil en la era del exceso visual. Revista de Occidente, ISSN 0034-8635, № 373, 2012, pp. 27-47.

Quintar, E. (2006). La enseñanza como puente a la vida. México D.F.: Instituto Pensamiento y cultura en América Latina.

Quintar, E. (2008). Didáctica no parametral. Sendero hacia la descolonización. México D.F., México: Instituto Pensamiento y cultura en América Latina.

Rancière, J. (2011). El destino de las imágenes. Buenos Aires, Argentina: Prometeo Libros.

Quintana, A. (2010). La hibridación de lo real: la huella digital. En Torregrosa, M. (Coordinadora). Imaginar la realidad. Ensayos sobre la representación de la realidad en el cine, la televisión y los nuevos medios. (Pp. 13 -21). Zamora, España: Comunicación Social Ediciones y Publicaciones. 